\title{
ABELHA AFRICANIZADA (Apis mellifera L.) EM ÁREAS URBANAS NO BRASIL: NECESSIDADE DE MONITORAMENTO DE RISCO DE ACIDENTES
}

\author{
Angela Mingozzi Martins dos Santos \\ Bióloga - Doutora em Parasitologia (Entomologia Médica) \\ Universidade Estadual de Campinas (UNICAMP) - Campinas/SP - Brasil \\ $\triangle$ angela.mingozzi@gmail.com \\ Elisa Cimitan Mendes \\ Bióloga - Doutoranda em Entomologia \\ Universidade de São Paulo (USP) - Ribeirão Preto/SP - Brasil
}

\section{Resumo:}

As abelhas constituem um dos principais grupos de animais associados à polinização de diversasplantas nativas e cultivadas, à regeneração de ecossistemas fragmentados e à apicultura, com destaque para Apis mellifera L., espécie exótica introduzida no Brasil no século XIX.Após o cruzamento das subespécies de Apis mellifera de origem europeia com a subespécie africana Apis m. scutellata, houve a aquisição de características herdadas da abelha africana (maior tolerância ao clima, alta capacidade de enxameação, etc.). Também foi herdado o comportamento de maior "agressividade", umnovo desafio para a apicultura, que exigiu readaptações no setor. As abelhas africanizadas nidificam em locais variados, tanto em áreas urbanas como rurais, o que favorece a ocorrência de acidentes com a população humana ou animal. Inúmeros casos já foram registrados, tornando-se esta uma importante questão para a saúde pública nacional. Este artigo contribui na reflexão para identificar medidas de planejamento e tomada de decisão, para a redução de acidentes, em tempo oportuno, e propor soluções, contando com instrumentos como o geoprocessamento, ligados a Sistemas de Informações Geográficas, a fim de se incrementar medidas para o monitoramento, prevenção, controle e mitigação dos acidentes com abelhas africanizadas em áreas de risco, obtendo-se assim maior agilidadede informações, tanto para prevenção quanto para ações de primeiros socorros em casos de acidentes já ocorridos.Sugere-se a elaboração de metodologia de notificação e investigação de eventos adversos associados às abelhas, atualizados no tempo e no espaço, para o controle da propagação das mesmas no ambiente urbano e rural.

Palavras-chave: Apis mellifera; Risco de acidentes; Geoprocessamento; Fauna sinantrópica; Animais peçonhentos.

\section{AFRICANIZED HONEYBEE (Apis mellifera L.) IN BRAZILIAN URBAN AREAS: NEED OF ACCIDENT RISK MONITORING}

\begin{abstract}
:
Bees are one of the major groups of animals associated with pollination of different plants, crops, fragmented ecosystems regeneration and beekeeping, especially Apis mellifera L., an
\end{abstract}


exotic species introduced in Brazil in the XIX century. After crossing between European Apis mellifera subspecies and African Apis m. scutellata subspecies, some characteristics of the African bee were inherited (greater tolerance to climate, high swarming capacity, etc). It was also inherited a greater behavior of "aggressiveness", a new challenge for beekeeping, which required readjustments in the sector. Africanized honeybees nest in variable places, such as urban and rural areas, which favor the occurrence of accidents with human or animal populations. As numerous cases have already been registered, this subject has become an important issue for national public health. This article aims to contribute to the pursuit to identify planning and decision-making measures to reduce accidents, timely, and propose solutions with tools such as geoprocessing, linked to Geographic Information Systems, in order to improve measures for monitoring, prevention, control and mitigation of accidents with Africanized honeybees in risk areas, achieving higher agility in information, both for prevention and for first aid actions in case of accidents that already had been occurred. It is suggested the preparation of reporting methodology and the study of adverse events associated with bees, updated in time and space, to control the spread of these bees in both urban and rural environment.

Keywords: Apis mellifera; Accident risk; Geoprocessing; Synanthropic fauna; Venomous animals.

\section{ABEJA AFRICANIZADA (Apis mellifera L.) EN ÁREAS URBANAS DE BRASIL: NECESIDAD DE MONITOREO DEL RIESGO DE ACCIDENTES}

\section{Resumen:}

Las abejas son uno de los principales grupos de animales asociados a la polinización de plantas nativas y cultivos, regeneración de ecosistemas fragmentados y apicultura, especialmente la Apis mellifera L., especie exótica introducida en Brasil en el siglo XIX. Después del cruce de las subespecies de Apis mellifera de origen europeo y la subespecie africana Apis m. scutellata, hubo características heredadas de la abeja africana (mayor tolerancia al clima, alta capacidad para enjambre, etc.). También ha sido heredado el comportamiento de más "agresividad", que exigió reajustes en la apicultura. Las abejas africanizadas se anidan tanto en áreas urbanas como rurales, favoreciendo la ocurrencia de accidentes con la población humana o animal. Numerosos casos han sido registrados, convirtiéndose esto en un problema importante para la salud pública nacional. El objetivo de este artículo es contribuir a la reflexión para identificar medidas de planificación y toma de decisiones para reducir los accidentes, y proponer soluciones, con herramientas como el geo procesamiento, con el fin de aumentar medidas para la monitorización, prevención, control y mitigación de accidentes con abejas africanizadas en zonas de riesgo obtenién dose mayor agilidad de informaciones tanto para prevención como para acciones de primeros auxilios en caso de accidentes ya ocurridos. Se sugiere la elaboración de metodología de notificación e investigación de eventos adversos asociados a las abejas, actualizadas en el tiempo y espacio, para el control de la propagación de las mismas en el entorno urbano y rural.

Palabras clave: Apis mellifera; Riesgo de accidentes; Geoprocesamiento; Fauna sinantrópica; Animales venenosos. 


\section{INTRODUÇÃO}

As abelhas (Hymenoptera: Apoidea) estão entre os grupos de animais associados à visitação de flores de espécies arbóreas, epífitas e outras, destacando-se entre os principais insetos polinizadores, que em conjunto com as aves e alguns mamíferos são transportadores de pólen (FRANCESCHINELLI et al., 2003; SILVA et al., 2014). De modo especial, as abelhas atuam na polinização das espécies de angiospermas, tanto pelo número como pela diversidade de plantas polinizadas, sendo que desse processo depende a formação de frutos e sementes. Em consequência, a apifauna nativa por cooperar na manutenção da base da cadeia alimentar, na perpetuação e riqueza das comunidades vegetais, desempenha importante papel na preservação e manutenção dos diversos ecossistemas dos diferentes biomas das regiões tropicais e subtropicais (PEREIRA e SOUSA, 2015; RAMBALDI e OLIVEIRA, 2003; SILVA et al., 2014). Assim, a fauna de polinizadores, em particular as abelhas, tanto as espécies nativas (como as abelhas sem ferrão ou Meliponídeos) quanto as exóticas do gênero Apis (Linnaeus), família Apidae,contribuem na regeneração de ecossistemas (biodiversidade e estabilidade) afetados por fatores naturais ou antrópicos (PEREIRAe SOUSA, 2015;RAMBALDIe OLIVEIRA, 2003; SILVA et al., 2014).

Há algumas décadas, a apicultura brasileira tem por principal suporte as populações polihíbridas de Apis mellifera L., conhecidas como abelhas africanizadas. Essas populações são resultantes dos cruzamentos naturais, embora acidentais, entre a abelha africana Apis melliferas cutellata Lepeletier com algumas subespécies europeias de Apis mellifera L.(A.B.E.L.H.A., 2015;ALMEIDA, 2008; PAULA NETO e ALMEIDA NETO, 2006; PEDROSO e FEITOSA, 2013; SANDES JÚNIOR, 2007; SEBRAE, 2011).

As populações de abelhas africanizadas possuem características biológicas predominantemente herdadas das abelhas africanas, principalmente a alta produtividade quando comparadas às abelhas europeias, além do forte comportamento de defesa ou "agressividade",a alta capacidade de enxameação, maior tolerância ao clima tropical e maior resistência a pragas e patógenos (A.B.E.L.H.A., 2015; FAQUINELLO, 2007;PAULA NETO e ALMEIDA NETO, 2006; PEDROSO e FEITOSA, 2013;SEBRAE, 2011).Uma das causas do aumento de produtividade na apicultura nacional foi o grande empenho dos apicultores em aperfeiçoar a sua própria experiência anterior com as populações de Apis mellifera de origem europeia, reformulando as técnicas de criação das abelhas e de produção de mel. Para isso contaram com respaldo técnico-científico, como o conhecimento da biologia e o comportamento das abelhas, para mitigar os impactos negativos iniciais (ex: sua maior 
"agressividade"), inclusive com ocorrência de acidentes com humanos e com animais domésticos, algumas vezes fatais (A.B.E.L.H.A., 2015; FAQUINELLO, 2007; PAULA NETO e ALMEIDA NETO, 2006; SEBRAE, 2013).

Entre alguns dos fatores que contribuíram para dar continuidade aos progressos no setor da apicultura destacam-se: a interação entre produtores e pesquisadores nos congressos e simpósios; a criação de concursos premiando novos inventos; a liberação de créditos para a atividade; a participação do País em eventos internacionais; o investimento em pesquisas; a criação da Confederação Brasileira de Apicultura em 1967; a valorização progressiva de outros produtos apícolas. Assim, o desenvolvimento da criação racional das abelhas para produção de mel possibilitou a comercialização de vários outros produtos, tais como: própolis, pólen apícola, geleia real, rainhas, abelhas parapolinização, apitoxina (veneno de abelha), cera e inclusive a comercialização de enxames e crias. E, o Brasil passou a se destacar no cenário internacional de controle das abelhas africanizadas (EMBRAPA, 2002; IBAMA, 2006; PEDROSO e FEITOSA, 2013; SEBRAE, 2011; SILVA e PEIXE, 2008).

O presente artigo foi elaborado tendo em conta a importância da apicultura nacional que desde a década de 1960, tem-se posicionado no ranking das quinze maiores produções mundiais de mel, e que a apicultura nacional é reconhecida como importante atividade zootécnica que proporciona benefícios sociais, como geração de emprego e renda no campo e também a diminuição do êxodo rural e benefícios econômicos, como a diversificação da propriedade rural. Além destes a apicultura traz benefícios ambientais, promovendo o crescimento da agricultura familiar e uso de forma sustentável dos recursos naturais (A.B.E.L.H.A., 2015; PAULA NETO e ALMEIDA NETO, 2006; PEDROSO e FEITOSA, 2013; SEBRAE, 2011; SILVA e PEIXE, 2008). As populações polihíbridas de Apis mellifera, abelha africanizada, pertencente à família Apidae (abelhas, mamangavas, abelhas das orquídeas e abelhas sem ferrão), em conjunto com outras espécies das famílias Vespidae e Formicidae, todas da mesma ordem Hymenoptera, são caracterizadas como insetos peçonhentos (A.B.E.L.H.A., 2015; CORREIA-OLIVEIRA et al., 2012; WINSTON, 2003).

O artigo foi desenvolvido baseando-se: 1- na Instrução Normativa (IN) IBAMA nº 141 (IBAMA, 2006), de 19 de dezembro de 2006 (D.O.U. de 20/12/06), que regulamenta o controle e o manejo ambiental da fauna sinantrópica nociva; 2-na Portaria $\mathrm{n}^{\circ} 1.138$, de 23 de maio de 2014 (BRASIL, 2014b), que define as ações e os serviços de saúde voltados para vigilância, prevenção e controle de zoonoses e de acidentes causados por animais peçonhentos 
e venenosos, de relevância para a saúde pública; 3- em fontes de informação técnica e científica, disponíveis na literatura especializada, em sites públicos ou privados online.

A contínua ocorrência de acidentes humanos associados à abelha africanizada e a gravidade dos mesmos para a saúde pública, em algumas regiões do país, justifica o objetivo deste artigo de contribuir na reflexão para a identificação de medidas que cooperem para o monitoramento do risco de acidentes, em tempo oportuno, ou seja, garantir as informações e ações necessárias para prevenir acidentes e também tomar as medidas cabíveis nos casos de acidentes já ocorridos com abelhas africanizadas.

\section{DESENVOLVIMENTO}

\section{I.1-Abelha africanizada (Apis mellifera L.)}

A história da introdução das abelhas da espécie Apis mellifera L. no Brasil é peculiar e está relatada em diferentes meios de comunicação, como em publicações científicas (DE JONG, 1996; MELLO et al., 2003; PAULA NETO e ALMEIDA NETO, 2006),boletins técnicos (SEBRAE, 2011), sites de instituições públicas de pesquisa e ensino (Embrapa, Sebrae e Unesp) e também em sites de organizações sociais (A.B.E.L.H.A., 2015). Esses autores corroboram na informação da introdução das subespécies exóticas de abelhas Apis mellifera de origem europeia (A. mellifera ligustica Spinola, A. m. caucasica Gorbachev, A. m. carniça Pollmann e A. m. mellifera L.) trazidas pelos imigrantes em meados do século XIX. Também a subespécie de origem africana (Apis mellifera scutellata, Lepeletier) foi introduzida no país em 1956, com objetivo de estudos científicos para melhoramento da apicultura nacional. As populações polihíbridas de Apis mellifera são resultantes dos cruzamentos naturais, embora acidentais, entre a abelha africana Apis m. scutellata e as subespécies europeias de Apis mellifera L. (A.B.E.L.H.A., 2015; ALMEIDA, 2008; DE JONG, 1996; FAQUINELLO, 2007; PAULA NETO e ALMEIDA NETO, 2006; PEDROSO e FEITOSA, 2013; SANDES JÚNIOR, 2007; SEBRAE, 2011). Essas populações apresentam características predominantes das abelhas africanas, tais como rusticidade e maior capacidade de enxamear e de defesa ("agressividade"), com maior potencial de adaptação, o que explica sua expansão em diversos ecossistemas americanos (CARNEIRO, 2010).

As populações polihíbridas de Apis mellifera passaram a ser conhecidas como abelhas africanizadas, estando presentes em todo o território nacional. A partir do Brasil se dispersaram para toda a América do Sul (com exceção do Chile), a América Central e parte da América do Norte(DE JONG, 1996; MISTRO et al., 2005). 
Desta forma, as populações polihíbridas de Apis mellifera (abelha africanizada) são caracteristicamente espécies invasoras exóticas, por introdução antrópica.

\section{I.2- Apifauna nativa e exótica: serviços ecossistêmicos}

No Brasil estima-se que existam mais de 2.500 espécies de abelhas distribuídas em cinco famílias (figura 1), incluídas nas mais de 20.000 espécies descritas no mundo (SILVA et al., 2014). Entre os esforços para o conhecimento, divulgação e conservação da fauna de Apoidea no país, destaca-se o material publicado em 2014, pela Universidade de São Paulo (USP), como parte do Projeto "Conservação e Manejo de Polinizadores para uma Agricultura Sustentável, através da abordagem Ecossistêmica”. Trata-se do Guia Ilustrado das Abelhas Polinizadoras no Brasil. Consta nesse documento que "as abelhas respondem pela polinização de mais de $50 \%$ das plantas das florestas tropicais e que no cerrado podem chegar a polinizar mais de 80\% das espécies vegetais" (SILVA et al., 2014, p.16). Apesar da importância ecológica, ainda é incipiente a publicação de estudos científicos (qualitativos e quantitativos) referentes ao levantamento das espécies, biologia e ecologia da apifauna do Brasil (BATISTA, 2015; BRASIL, 2001; MELLO et al., 2003; PEREIRA e SOUSA, 2015; RAMBALDI e OLIVEIRA, 2003; SILVA et al., 2014).

Os fatores antrópicos responsáveis pela fragmentação dos ecossistemas (ex.: desmatamento, uso indiscriminado de agrotóxicos, queimadas e etc.) afetam, direta ou indiretamente, a existência das espécies de abelhas, visitantes florais polinizadores, acarretando efeito negativo na produção de frutos e sementes. Em consequência, verificam-se impactos negativos na sobrevivência de outros animais que dependem dessa produção. FRANCESCHINELLI et al. (2003, p.277) consideram que "além dos animais silvestres, $o$ serviço da polinização também beneficia o homem, uma vez que muitas plantas cultivadas necessitam de polinizadores nativos para produção de frutos e sementes". 
Figura 1 - Famílias de abelhas que ocorrem no Brasil

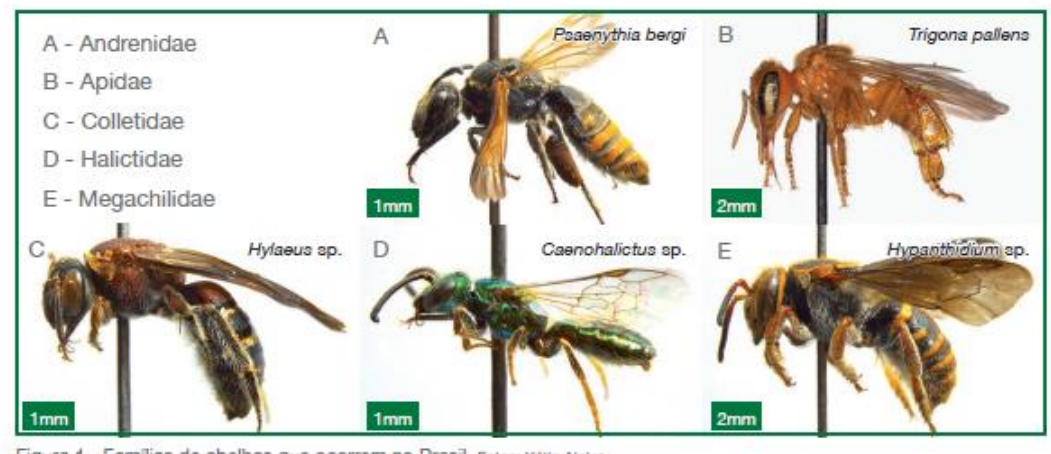

Fonte: SILVA et al., 2014, p.7

As espécies de abelhas nativas, assim como as espécies exóticas do gênero Apis introduzidas no território brasileiro desde meados do século XIX, têm cooperado para o desenvolvimento dos agroecossistemas (ex.: polinização de pomares, cultivos agrícolas e da flora silvestre). Em âmbito nacional e mundial, as abelhas nativas e as exóticas são responsáveis pela polinização de $73 \%$ do cultivo de plantas utilizadas de forma direta ou indireta na alimentação humana (SILVA et al., 2014). A figura 2 apresenta as culturas agrícolas que são polinizadas pelas populações de Apis mellifera e as plantas que lhes são atrativas.

A apifauna exótica e de algumas espécies nativas, no desempenho do seu papel e na sua distribuição ecossistêmica, podem vir a ocasionar os acidentes entre os seres humanos e as abelhas, uma vez que estas estão presentes em ambientes cada vez mais característicos de áreas urbanas. 
Figura 2- Culturas agrícolas polinizadas pela abelha Apis mellifera L. no território brasileiro e plantas que lhes são atrativas.

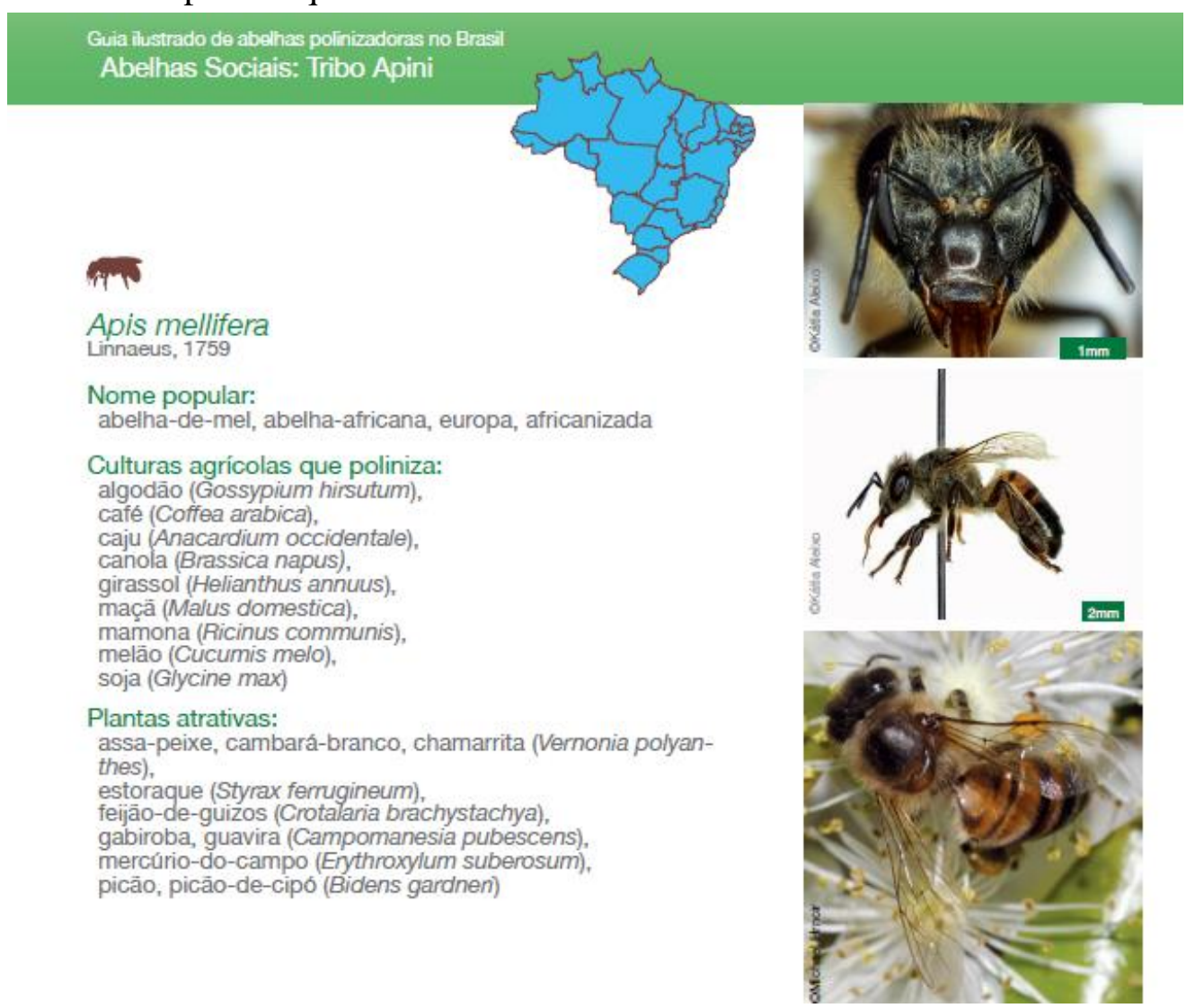

Fonte: SILVA et al., 2014, p.25.

\section{I.3- Abelhas africanizadas (Apis mellifera L.) no âmbito da Estratégia Nacional} sobre Espécies Exóticas Invasoras- Resolução CONABIO no 5 (21/10/2009)

No Brasil, o conceito de fauna exótica invasora assumido pelo Ministério do Meio Ambiente - MMA (BRASIL,2012) está de acordo com a Convenção sobre Diversidade Biológica - CDB, que define "espécie exótica é toda espécie que se encontra fora de sua área de distribuição natural". E, segundo o qual Espécie Exótica Invasora "é definida como sendo aquela que ameaça ecossistemas, hábitats ou espécies. Estas espécies [invasoras], por suas vantagens competitivas, favorecidas pela ausência de inimigos naturais têm capacidade de se proliferar e invadir ecossistemas, sejam eles naturais ou antropizados". Também o art $2^{\circ}$ da Instrução Normativa IBAMA $\mathrm{n}^{\circ} 141$, no inciso III, define como fauna exótica invasora "animais introduzidos a um ecossistema do qual não fazem parte originalmente, mas onde se adaptam e passam a exercer dominância, prejudicando processos naturais e espécies nativas, além de causar prejuízos de ordem econômica e social" (IBAMA, 2006, p.1). 
O Ministério do Meio Ambiente - MMA disponibiliza no seu site oficial (BRASIL, 2012um histórico das etapas para o desenvolvimento da "Estratégia Nacional sobre Espécies Exóticas Invasoras", aprovada na Resolução no 5, de 21 de outubro de 2009da Comissão Nacional de Biodiversidade (CONABIO, 2009).Esse histórico é apresentadode forma resumida a seguir:

Em 2003 - Sistematização das informações disponíveis sobre Espécies Exóticas Invasoras e divulgação do mesmo, através da elaboração, pelo Ministério do Meio ambiente MMA, do "Primeiro Informe Nacional sobre Espécies Exóticas Invasoras". Neste consta o levantamento relacionado às espécies exóticas invasoras no país, com informações sobre sua distribuição geográfica e a capacidade instalada no país para tratar o problema.

De 2004 a 2005- Conclusão do Primeiro Informe Nacional sobre Espécies Exóticas Invasoras, com diagnósticos sobre as espécies exóticas invasoras atuais e potenciais e a existência no País de estrutura de prevenção e controle.

2005- Realização do I Simpósio Brasileiro sobre Espécies Exóticas Invasoras, que amplia a disseminação das informações levantadas pelo Informe Nacional. Diversos segmentos da sociedade são envolvidos na discussão dos principais temas: a legislação nacional e a regulamentação do uso de espécies de valor econômico; prioridades para financiamento; sensibilização e educação; controle e monitoramento; análise de risco; prevenção e detecção precoce. O evento foi realizado pelo MMA e pelo IBAMA, em parceria com a Fiocruz, Embrapa, Universidade Federal de Viçosa, Instituto Oceanográfico da USP, TNC e Instituto Hórus.

2006 - Criação da Câmara Técnica Permanente sobre Espécies Exóticas Invasoras CTPEEI - no âmbito da Comissão Nacional de Biodiversidade - CONABIO (Deliberação CONABIO $n^{\circ} 49$, de 30 de agosto de 2006). A CTPEEI tem entre os seus objetivos o de identificação da ocorrência e distribuição de espécies exóticas invasoras, avaliando seus impactos ao meio ambiente e à saúde humana.

2009 - Aprovação da "Estratégia Nacional sobre Espécies Exóticas Invasoras"pela CONABIO, por meio da Resolução $n^{\circ}$ 5, de 21 de outubro de 2009, elaborada pela CTPEEI, incluindo elementos de prevenção, controle, políticas e instrumentos legais, conscientização pública, capacitação técnica, pesquisa e financiamento. 
2012 - Realização da primeira reunião do Comitê de Aconselhamento sobre Espécies Exóticas Invasoras, articulação e integração frente ao problema, contando com a participação de representantes do Departamento de Conservação da Biodiversidade - DCBio, do Instituto Brasileiro do Meio Ambiente e Recursos Naturais - IBAMA e do Instituto Chico Mendes de Conservação da Biodiversidade - ICMBIO. Esse comitê tem por objetivo reunir esforços e traçar uma agenda comum de trabalho entre a Secretaria de Biodiversidade e Floresta - SBF, o IBAMA e o ICMBio.

2013 - Aprovação da Resolução CONABIO nº 6, de 03 de setembro de 2013, que dispõe sobre as Metas Nacionais de Biodiversidade para 2020.

A Nota Técnica emitida pelo Centro de Apoio às Promotorias de Meio Ambiente e Urbanismo do Estado da Bahia (CEAMA, 2016), esclarece que em 2011, foi publicada uma lista de EEI(espécies exóticas invasoras) para o Nordeste Brasileiro, na qual a abelha africanizada está classificada como tal, conforme a Estratégia Nacional sobre Espécies Exóticas Invasoras aprovada pela Resolução CONABIO n ${ }^{0} 5$ de 21 de outubro de 2009. Nesse documento, que disponibiliza instruções para a criação de regulamentação visando o Controle e Manejo Ambiental como atividade de rotina no combate aos acidentes com abelhas africanizadas nos centros urbanos do Estado da Bahia, consta que:

\footnotetext{
[...] o Ministério Público do Estado da Bahia, em função das inúmeras denúncias encaminhadas pela população sobre acidentes provocados por abelhas africanizadas na área urbana, vem participando ativamente do processo de discussão sobre a assunção de responsabilidade do setor público não somente quanto ao atendimento à população, mas, sobretudo, quanto ao estabelecimento de estratégias para o manejo adequado dessa espécie de abelha, prevenindo, portanto, acidentes e agravos à saúde pública. Para tanto, a presente Nota Técnica busca indicar medidas para a criação de mecanismos legais, que possibilitem a regulamentação do atendimento aos acidentes envolvendo abelhas africanizadas nos centros urbanos, vez que têm representado risco iminente ao meio ambiente e a saúde pública na cidade do Salvador e no Estado da Bahia (CEAMA, 2016, p.1).
}

Trata-se de uma iniciativa inédita do Ministério Público em nível Estadual, que, em consonância com a Meta 9 da Resolução CONABIO nº 6 (03/09/2013), apresenta instruções para a criação de regulamentação visando o Controle e Manejo Ambiental como atividade de rotina no combate aos acidentes com abelhas africanizadas nos centros urbanos do Estado da Bahia. 


\section{I.4- Abelhas africanizadas (Apis mellifera $\mathrm{L}_{\text {.) }}$ : insetos peçonhentos integrantes da} fauna sinantrópica nociva

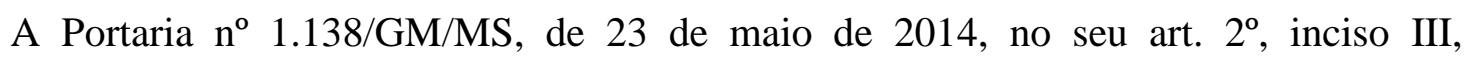
considera entre os animais de relevância para a saúde pública, aqueles que se apresentam como venenoso ou peçonhento (BRASIL, 2014b). Os indivíduos da espécie Apis mellifera L. enquadram-se na definição de animais peçonhentos por possuírem um aparato no abdômen, com ferrão e um saco de veneno (CORREIA-OLIVEIRA et al., 2012; A.B.E.L.H.A., 2015). Quando esses insetos percebem uma ameaça, perturbação direta (na colônia) ou indireta (na proximidade da colônia), seja pela presença de outro animal ou do ser humano, atuam com um comportamento de defesa, inoculando veneno por meio do ferrão no agente perturbador (A.B.E.L.H.A., 2015; CORREIA-OLIVEIRA et al., 2012).Esse comportamento se traduz na linguagem humana como "agressividade" das abelhas. Fator agravante ocorre, quando partes das abelhas guarda inicia o desencadeamento de uma reação de defesa em massa, com a liberação de feromônio contido nas mandíbulas e ferrão (CORREIA-OLIVEIRA et al., 2012). Assim, ao perceberem a ameaça, as abelhas africanizadas costumam atacar em enxames, inoculando grande quantidade de veneno, por meio de múltiplas picadas. No ato da picada, o ferrão(figura 3)se separa do corpo da abelha (autotomia), acarretando a morte da abelha, mas o ferrão inserido no corpo da vítima integra o conjunto do segmento distal do abdômen da abelha que é constituído por musculatura e gânglios próprios, e assim continua injetando veneno (apitoxina). Esse veneno possui vários componentes com atividades tóxicas (ex: hialuronidases, fosfolipases, peptídeos ativos como a melitina, apamina e a histamina) que atuam em particular no sistema nervoso da "vítima" (BATISTA, 2015; CEAMA, 2016; CORREIA-OLIVEIRA et al., 2012).

Os acidentes com abelhas, além da dor, podem causar reações alérgicas, sendo que a reação tóxica sistêmica provocada pela apitoxinase caracteriza inicialmente por manifestações dermatológicas típicas de intoxicação histamínica (pequenos inchaços localizados, casos de hipersensibilidade, hemorragias, inflamação de vias aéreas). As reações alérgicas podem ou não evoluir para um quadro de choque anafilático, levando a óbito. Em consequência, a prontidão no atendimento médico é fundamental para minimizar o risco decorrente da intensidade dessas reações (CORREIA-OLIVEIRA et al., 2012).

A intensidade e a gravidade dessas reações variam de pessoa para pessoa, segundo fatores como: a idade e sensibilidade do indivíduo, o local e o número de ferroadas 
(BATISTA, 2015; CEAMA, 2016; CORREIA-OLIVEIRA et al., 2012).De acordo com CEAMA (2016,p.3), "as manifestações clínicas podem ser alérgicas (mesmo com uma única picada) e/ou tóxicas (múltiplas picadas). As reações tóxicas locais estão associadas ao local da picada, ao número de ferroadas, às características e o passado alérgico do indivíduo atingido”.

Figura 3: Detalhes da região terminal do abdome da abelha A. mellifera

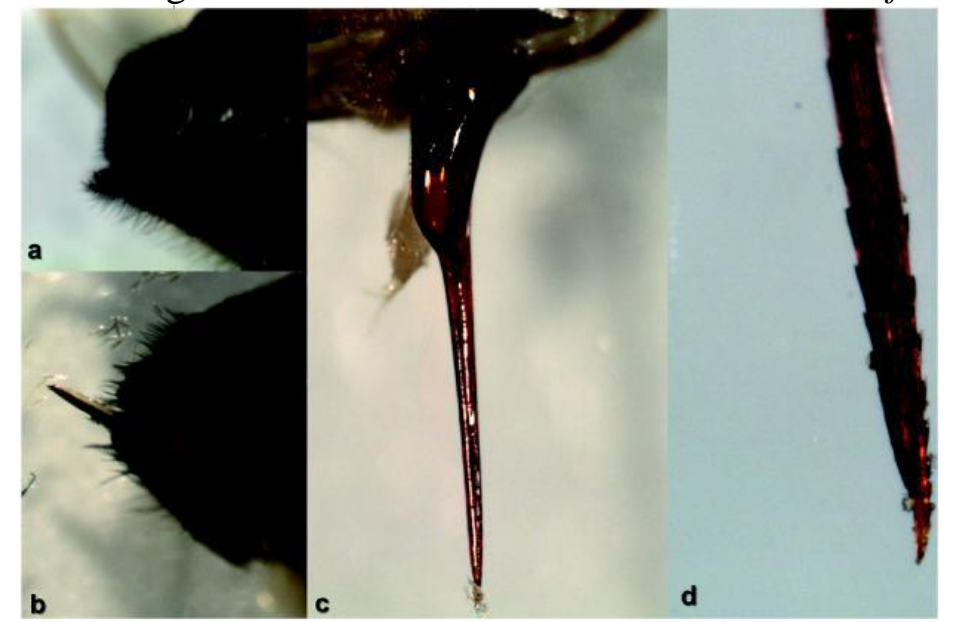

Legenda: (a)- Ferrão recolhido; (b)- Ferrão exposto; (c)- Um ferrão extraído; (d)Detalhe da parte apical do ferrão, mostrando as extremidades serrilhadas.

Fonte: CORREIA-OLIVEIRA et al., 2012, p.17.

Batista (2015) estudou o perfil epidemiológico de 260 casos de acidentes com abelhas e vespas atendidos no Hospital de Emergência e Trauma de Campina Grande e notificados pelo CEATOX-CG, entre janeiro de 2012 (100) a dezembro de 2013 (160). Esse pesquisador verificou que 49 pacientes $(18,85 \%)$ desenvolveram quadro de reações alérgicas, sendo 67,3 $\%$ ocasionados por picadas de abelhase os demais por vespas. $\mathrm{O}$ mesmo constatou o predomínio de acidentes nos meses de janeiro (16\%) e fevereiro (16\%) etambém a quantidade de picadas foi maior nas estações de primavera-verão. Nesse estudo, constatou-se que $69,4 \%$ dos acidentes ocorreram no ambiente urbano.

Em dezembro de 2015, como parte da programação dos seus 35 anos, o Sistema Nacional de Informações Tóxico-Farmacológicas (Sinitox/Icict/Fiocruz) lançou o seu site (http://sinitox.icict.fiocruz.br/) em nova versão, mais dinâmica e interativa, contendo informações de interesse a todos os públicos, desde a criança ao pesquisador. O Sinitox conta com 32 unidades situadas em 30 municípios brasileiros, sendo os registros dos acidentes feitos pela Rede de Informação e Assistência Toxicológica (RENACIAT). Além de disponibilizarem os dados epidemiológicos de uma dada região, essas unidades (Centros de 
Informação e Assistência Toxicológica - CIAT) são fundamentais nos casos de acidentes envolvendo animais venenosos ou peçonhentos de relevância para a saúde pública. Sua missão consiste também na orientação de outros profissionais de saúde, quanto às condutas adequadas em tais situações, além de informar a população sobre a maneira de se prevenir de acidentes e como atuar caso ocorram.

Segundo CORREIA-OLIVEIRA et al. (2012, p. 15):

Em São Paulo desde o ano 1993, as abelhas passaram a ser vistas como "animal agressor" na ficha de investigação de acidentes por animais peçonhentos do Centro de Vigilância Epidemiológica (CVE) "Prof. Alexandre Vranjac", da Secretaria de Estado da Saúde de São Paulo (MELO; SILVA; NATAL, 2003). Verificou-se que desde sua criação até o ano 2011, o CVE registrou aproximadamente 10.000 casos de acidentes com abelhas africanizadas.

Em nível Nacional, a INIBAMA n ${ }^{\circ} 141$ de 19 de dezembro de 2006 regulamenta, no seu artigo $1^{\circ}$, o controle e o manejo ambiental da fauna sinantrópica nociva e considera a necessidade de:

$\S 1^{\circ}$ - Declarações locais e temporais de nocividade de populações de espécies da fauna deverão, sempre que possível, ser baseadas em protocolos definidos pelos Ministérios da Saúde, da Agricultura ou do Meio Ambiente. §2 - Com base no protocolo referido no parágrafo anterior, populações de espécies sinantrópicas podem ser declaradas nocivas pelos órgãos federal ou estaduais do meio ambiente ou, ainda, pelos órgãos da Saúde e Agricultura, quando assim acordado com o órgão do meio ambiente (IBAMA, 2006).

Já no seu artigo $2^{\circ}$ a IN IBAMA n 141 (IBAMA, 2006) define no inciso IV como fauna sinantrópica "populações animais de espécies silvestres nativas ou exóticas, que utilizam recursos de áreas antrópicas, de forma transitória em seu deslocamento, como via de passagem ou local de descanso; ou permanente, utilizando-as como área de vida". E, no seu inciso V define como fauna sinantrópica nociva a "fauna sinantrópica que interage de forma negativa com a população humana, causando-lhe transtornos significativos de ordem econômica ou ambiental, ou que represente riscos à saúde pública".

A nota técnica do CEAMA (2016, p.2), no seu item II.3, comenta, que:

A Instrução Normativa 141 de 19 de novembro de 2006, do IBAMA, que Regulamenta o controle e o manejo ambiental da fauna sinantrópica nociva, incluem nesse grupo de modo geral, as abelhas.

Segundo o Art $1^{\circ}, \S 1^{\circ}$ e $\S 2^{\circ}$, dessa Instrução Normativa, a nocividade das abelhas africanizadas deve ser declarada por parte dos Ministérios da Saúde, da Agricultura 
ou do Meio Ambiente, e até mesmo pelos órgãos federais ou estaduais do meio ambiente ou, ainda, pelos órgãos da Saúde e Agricultura, quando assim acordado com o órgão do meio ambiente competente.

Diante do exposto, entende-se que as abelhas africanizadas podem ser consideradas como fauna sinantrópica nociva, uma vez que a espécie interage nos centros urbanos de forma negativa com a população humana, causando-lhe transtornos significativos que representam riscos à saúde pública.

Destarte, é necessária para seu manejo com possível erradicação, uma declaração da nocividade dessas abelhas, exarada por um órgão público competente nos moldes das normas antes mencionadas de modo que além de classificá-las como EEI também seja declarada como fauna sinantrópica nociva.

O texto disponibilizado no site oficial do Ministério da Saúde com o título "Esclarecimento sobre a Portaria n ${ }^{\circ}$ 1.138/GM/MS, de 23 de maio de 2014", explica que:

A consolidação desta norma ocorreu após amplo processo de discussão entre as três esferas de governo (União, Estados e Municípios) do setor saúde ao longo dos últimos quatro anos. A proposta também foi submetida à apreciação da sociedade civil no ano de 2013, por meio de consulta pública. Este processo foi conduzido, paritariamente, de acordo com competências definidas em lei para o Sistema Único de Saúde (SUS), entre o Conselho Nacional de Secretarias Municipais de Saúde (CONASEMS), o Conselho Nacional de Secretários Estaduais de Saúde (CONASS) e a Secretaria de Vigilância em Saúde do Ministério da Saúde (SVS/MS), sendo a norma submetida à aprovação da Comissão Intergestores Tripartite - CIT, que a aprovou e pactuou as diretrizes ali estabelecidas (BRASIL, 2014a).

O enquadramento das abelhas africanizadas (Apis melífera L.) como insetos peçonhentos integrantes da fauna sinantrópica nociva, reforça a necessidade da atuação de profissionais de saúde, em nível local, bem capacitados e informados quanto à conduta (ex.: primeiros cuidados, estabilização do paciente e tratamento sintomático) para que se obtenha a melhor evolução possível do quadro de acidentes com abelhas africanizadas. Para tanto, ressalta-se o papel dos Centros de Informação e Assistência Toxicológica (CIAT) como centros de referência.

\section{I.5- Modelos de dispersão em Apismellifera: enxame viajante e o risco à saúde} pública

Publicações científicas como a de SOARES et al. (2012)fornecem informações sobre o comportamento de dispersão de Apis mellifera:

Muito bem adaptada às condições tropicais, essa abelha africanizada apresenta
basicamente dois modelos de dispersão que têm favorecido a sua sobrevivência e a
expansão no continente americano. Migrando a uma velocidade de $400-500 \mathrm{~km}$ por
ano, atingiu o Texas (USA) em outubro de 1990 e rapidamente se espalhou para a
costa oeste chegando ao sul da California. Recentemente atingiu a Florida na costa 
leste. Quando as condições de fluxo de alimento são ótimas, as abelhas africanizadas trabalham incessantemente. Expandem sua população que, em alguns casos, chega a 120 mil abelhas e podem produzir uma divisão natural da colônia pelo processo de enxameação. Neste processo ocorre a formação de uma nova rainha e a metade das abelhas da colônia sai com a rainha velha à procura de um local adequado de nidificação para estabelecer a sua nova moradia. Quando o fluxo de alimento diminui, para não morrerem de fome as abelhas abandonam a colmeia e vão em busca de um outro local que apresente condições favoráveis de sobrevivência(SOARES et al., 2012, p.1).

Também a experiência cotidiana dos Centros de Zoonose municipais no atendimento de solicitações da população para o manuseio de abelhas africanizadas (retirada de colmeias e enxames) fornece muitas informações referentes ao comportamento de enxameação dessas abelhas. Tais informações podem ser úteis na identificação de estratégias mais eficientes de manejo e orientação à população. Assim, MELLO et al.(2003) realizaram estudo com dados disponibilizados pela Seção de Controle de Vetores do "Centro de Controle de Zoonoses da Secretaria Municipal de Saúde de São Paulo" referentes à remoção de colônias (abelhas instaladas no local, com presença de favos de mel e de cria) e de enxames viajantes (aglomerado de abelhas envolvendo a rainha e que pousam nos mais diversos locais até encontrar abrigo adequado onde futuramente é instalada a colônia definitiva), no período de 1994 a1997. O objetivo desse estudo foi identificar estratégias eficientes de manejo desses insetos e verificar locais mais frequentes de nidificação. Os autores verificaram que nos quatro anos analisados (1994 -1997), o número de solicitações foi de 3.061, sendo 1990 para remoção de colônias, 1024 para remoção de enxames viajantes e 47 por motivos indeterminados.

Segundo os estudos de MELLO et al.(2003), constata-se que os locais preferenciais de instalação de colônias da abelha africanizada foram os forros e o interior de paredes, enquanto a maior porcentagem dos enxames viajantes se instalaram em árvores e externamente às paredes. Esses autores concluíram que os períodos do ano com altas temperaturas e baixo índice pluviométrico estão relacionados à maior atividade das abelhas e ao maior número de enxames, propiciando maior contato com a população. Recomendam, ainda, que: objetos como caixas e tambores não devem ficar expostos; os abrigos em potencial para colônias e enxames (forros e paredes) devem ser vedados; as áreas arborizadas por servirem de refúgio para enxames merecem maior atenção e não se devem manusear enxames. Os mesmo autores descrevem:

[...]os enxames viajantes pousam em locais provisórios e iniciam o processo de localização de cavidades para instalação de nova colméia. As operárias voam nas redondezas e, ao encontrarem local adequado, comunicam ao enxame que, a seguir, 
parte para o novo abrigo. Devido ao pequeno período de permanência desses enxames nos locais provisórios, o número de locais de pouso de enxames viajantes, dos quais não se tem informação, é grande. Na maioria das vezes, quando a equipe atinge o local, o enxame já partiu para um novo abrigo ou o próprio munícipe cancelou a solicitação pelo mesmo motivo. Porém, quando as abelhas não encontram um local apropriado, podem iniciar a construção do ninho no mesmo ponto onde estão agrupadas(MELLO et al., 2003, p. 240).

O Relatório de Inteligência Analítico “Acidentes com abelhas: compreensão para prevenção" elaborado pelo SEBRAE (SEBRAE, 2013) descreve quais são os fatores que levam as abelhas a se defenderem e quais as medidas que devem ser tomadas para que se garanta uma segurança adequada no manejo e, também, nas cidades:

O número de acidentes com abelhas tem crescido muito no Brasil nos últimos anos. Dados apresentados nesse relatório mostram que no ano 2000 foram registrados 1.450 casos em todo o país e, em 2011, esse número passou para 9.447 casos. Os cuidados com a segurança no manejo são fundamentais e devem orientar as práticas apícolas como um todo. Entre as recomendações para a prevenção de acidentes está a observação da distância mínima de segurança de residências, locais de circulação de pessoas e instalações com animais presos para a instalação dos apiários. São muitos fatores que levam as abelhas a defenderem suas colmeias como vibrações ou cheiros fortes. Se as abelhas se sentirem ameaçadas as chances de ataques são certeiras tanto no campo, quanto nas cidades(SEBRAE, 2013, p.2).

Segundo MELLO et al. (2003), o cuidado com acidentes envolve a frequência de enxameações, que acontecem de três a quatro vezes ao ano, e a variabilidade de locais de nidificação em áreas urbanas. Esses locais aumentam o contato entre as abelhas e as pessoas. O contato direto entre os insetos e a população usualmente ocorre quando, inadvertidamente, indivíduos manipulam locais próximos aos ninhos das abelhas, atiram objetos e produtos químicos, tentam retirar ou destruir os ninhos sem proteção adequada ou, ainda, no contato eventual com um único inseto.

Desta forma, em concordância com SOARES (2012), CEAMA (2016),SEBRAE (2013) e MELLO et al.(2003), ressalta-se que os dois mecanismos, enxameação (três a quatro vezes ao ano) e abandono, apesar de refletirem o comportamento adaptativo da abelha africanizada pela sobrevivência de suas populações, atuam como fator de aumento de risco na ocorrência de acidentes com humanos na área urbana. Em particular, no início da primavera constata-se a ocorrência de maior número de enxames viajantes, por estímulo reprodutivo, pois rainhas iniciam um novo ciclo de reprodução. E, de acordo com alguns fatores, tais como o uso do solo no entorno da área do apiário, a disponibilidade floral, sua proximidade ao ambiente urbano, a existência de barreiras naturais ou não, os enxames viajantes podem encontrar no ambiente urbano, uma variedade de abrigos potenciais. Então, o posicionamento 
desses segundo os locais escolhidos como novo local de nidificação aumentam a probabilidade de acidentes em humanos.

\section{6- O uso de geotecnologias em estudos com Apis mellifera $\mathbf{L}$.}

No Brasil, ainda são incipientes os estudos com Apis mellifera L. Utilizando Geoprocessamento (técnicas matemáticas e computacionais) para o tratamento de informações geográficas, reunidas em bancos de dados socioeconômicos, de saúde e de meio ambiente em bases espaciais úteis ao planejamento.

Os instrumentos computacionais do Geoprocessamento, chamados de Sistemas de Informações Geográficas (SIGs), permitem realizar análises complexas ao integrar dados de diversas fontes e ao criar bancos de dados georreferenciados, possibilitando também a automatização da produção de documentos cartográficos. Entre as fontes de dados que podem ser processados nos SIGs, estão as imagens de sensoriamento remoto orbital utilizadas em estudos e levantamentos ambientais, agrícolas, cartográficos, florestais e urbanos. Devido à rapidez de processamento das fontes de dados e diversidade de ferramentas de análises espaciais, os SIGs apresentam-se como ferramentas de grande eficiência, possibilitando o monitoramento periódico de variáveis ambientais em diferentes escalas (locais, regionais e globais)(BARCELLOS e BASTOS, 1996; BARCELLOS e RAMALHO, 2002; CÂMARA e MEDEIROS, 1998; MANGABEIRA, 2002; SANTOS et al., 1997).

SANTOS (2011) avaliou a diversidade polínica no mel de Apis mellifera e a distância entre os fragmentos no entorno de apiários.Por meio do SIG, para cada área foram construídas cartas temáticas de uso e cobertura vegetal,permitindo identificar os processos culturais que interferem na heterogeneidade da paisagem. Para tanto, os fragmentos foram classificados em antrópico ou nativo, com base nas cartas temáticas. A influência da identidade e indicadores do padrão da paisagem na diversidade polínica do mel de Apis mellifera foi mensurada pelo número e densidade de fragmentos de vegetação antrópica e nativa e pela distância entre os fragmentos no entorno de apiários comerciais instalados na região sudoeste de Mato Grosso. Para SANTOS (2011), as análises dessas informações são úteis para auxiliar na gestão integrada da apicultura com o ambiente. $\mathrm{O}$ autor ressalta que estabelecer estratégias de gestão ambiental para o uso apícola em função da dinâmica do uso e cobertura vegetal é importante para a manutenção dessa atividade econômica e contribui com a conservação das principais espécies apícolas. 
SANDES JÚNIOR (2007),com o objetivo de conhecer e monitorar as áreas de ocorrência dos enxames migratórios de Apis mellifera L. na cidade de Salvador,Bahia, utilizou em sua metodologia técnicas de geotecnologias para: 1-mapear e georreferenciar essas áreas; 2- mapear e georreferenciar os locais de acidentes com seres humanos e animais; 3- identificar os fatores ambientais motivadores e/ou facilitadores da ocorrência desses enxames na região, por meio da sua correlação com variáveis demográficas e edafoclimáticas da área em estudo.Os dados foram obtidos pela Companhia de Polícia de Proteção Ambiental, Unidade Especializada da Polícia Militar da Bahia no projeto "SOS Abelhas". O autor comenta que "a distribuição espacial dos dados busca associar o evento ao local em que ele ocorreu ou foi gerado, enriquecendo a qualidade das informações obtidas sobre o estudo além de permitir avaliar a troca de influências com o meio. Essa distribuição pode ser feita de forma individual, quando o evento é representado por um ponto, ou em grupo, sendo as unidades representadas por áreas (bairros, setores censitários e municípios)" (SANDES JÚNIOR, 2007).Assim, foram georrefenciadas 590 ocorrências de enxames migratórios, no período de 2000 a 2004, distribuídos em 75 Zonas de Informações (ZIs) das 98 existentes em Salvador. Foram registrados no CIAVE (Centro de Informações Antiveneno) da Secretaria de Saúde do Estado da Bahia, durante o mesmo período, 316 acidentes com abelhas em humanos. Foi demonstrado que o aumento do número de ocorrências de enxames está relacionado à elevação da temperatura média mensal. Estes resultados são referentes às primeiras análises espaciais sobre o evento de enxames migratórios em uma metrópole brasileira e ocasionam a ampliação do conhecimento sobre estas situações e suas relações com a saúde pública e a área urbana (SANDES JÚNIOR, 2007).

CAMARGO (2011) desenvolveu uma metodologia por meio do uso do Sistema de Informações Geográficas (SIG), que permite o armazenamento de informações e a localização geográfica de apiários, assim como, a avaliação da superpopulação de colmeias, do seu manejo, da flora local e da ocupação do solo sobre a produção quantitativa e qualitativa de mel em nível local. Seu estudo foi desenvolvido em apiários de oito municípios da região oeste do Paraná.

PAULA (2009) comenta que "a atividade apícola não agride ao meio ambiente, é comprovadamente rentável se bem administrada, e pode ser desenvolvida em, praticamente, todo o espaço geográfico que possui condições de solo e clima favoráveis e uma rica florada, sendo uma atividade sustentável e de grande importância econômica". Assim, o mesmo 
desenvolveu, em 2008, uma metodologia em ambiente de SIG, em software livre, com o objetivo de contribuir na orientação da escolha de áreas para instalação de apiários no assentamento Padre Josimo Tavares, no Pará. Segundo PAULA (2009), a orientação na escolha dos locais para instalação dos apiários "visa otimizar a produção de mel e a polinização de zonas agrícolas, a fim de aumentar a produção agrícola e de acelerar o processo de recuperação da flora nativa em áreas degradadas".

BRITO (2014)aplicou o SIG na investigação da varroatose obtendo resultados úteis no direcionamento de ações em sanidade apícola com base no território. O mesmo avaliou a presença do ácaro Varroa destructor em abelhas Apis mellifera (africanizadas), em dois municípios do nordeste brasileiro, identificando possíveis variáveis ambientais e de manejo para a prevenção em sanidade apícola.

O autor comenta:

[...] a delimitação espacial denominada como Buffer corresponde à área com raio de $3 \mathrm{~km}$ do centro de cada apiário de Entre Rios - BA. Esta área foi demarcada de forma a sugerir a limitação do acesso de apiários migratórios nesta zona, como medida preventiva. Segundo Seeley (1995), as abelhas podem explorar as fontes de alimento até uma distância aproximada de $6 \mathrm{~km}$. No entanto, para que o trabalho de forrageamento seja eficiente, as fontes de alimento devem estar ao máximo de $3 \mathrm{~km}$ de distância das colônias, pois o desgaste metabólico em longos percursos pode ser maior do que o benefício com a apreensão do alimento (CAMARGO et al., 2002) (BRITO, 2014, p. 41)

Para BRITO (2014) “o diagnóstico da TI [Taxa de Infestação] do Varroa destructor é um procedimento simples que não exige altos investimentos laboratoriais, assim como o software em SIG utilizado nesta pesquisa, que é gratuito e de livre acesso ao público". O autor comenta que essa metodologia é passível de ser reaplicada por instituições de pesquisa ou extensão rural e de defesa, e que utilizá-la pode favorecer a detecção precoce de possíveis zonas de risco à varroatose e outras patologias associadas a este ácaro. Também ressalta a utilidade da metodologia para direcionar ações preventivas contra a disseminação de ácaros mais virulentos, assim como sugerir adequações de manejo.

BRITO (2014)ressalta a necessidade de elaboração de políticas públicas destinadas à manutenção da integridade da sanidade apícola por meio do zoneamento apícola em nível municipal. O autor conclui seu estudo com as seguintes sugestões para prevenir os impactos negativos ou reduzir a magnitude da varroatose:

i. Trocar rainhas de colônias com TIs superiores a 5\%, por rainhas originárias de colônias mais resistentes ao Varroa destructor;

ii. Redistribuir apiários evitando-se a criação de zonas de aglomeração, observadas pelo estimador de densidade de Kernel; 
iii. Apenas realizar a transferência de quadros entre colônias de procedência conhecida, em observação a resistência à varroatose e a ausência de sintomas para outras patologias;

iv. Investigar a área de cria das colônias, principalmente, os enxames fracos e sujeitos ao saque, pois podem estar altamente infestadas, sendo foco de disseminação do Varroa destructor ou outras patologias;

v. Adaptar válvula de escape para zangões no coletor de pólen, permitindo o transito dos zangões entre o ambiente interno e externo da colmeia, evitando a morte destes indivíduos no interior das colônias.

vi. Em casos agudos, aplicar produtos naturais de controle do Varroa destructor nas colônias com elevadas TIs e observar a existência de colônias infestadas em apiários a 1,5 km de distância, para tratamento simultâneo, sob risco de reinfestação; vii. Não expor as colônias diretamente ao Sol;

viii. Implantar programa de melhoramento com ênfase na seleção de colônias higiênicas, com baixa TI e boa produtividade;

ix. Evitar que apiários migratórios sejam implantados a menos de $3 \mathrm{~km}$ dos apiários existentes;

x. Atualizar anualmente o georreferenciamento dos apiários e a investigação epidemiológica por grupo de produtores(BRITO, 2014, p.50).

Com base nos estudos citados anteriormente, vislumbra-se o potencial da aplicação do Sistema de Informações Geográficas (SIG) ao monitoramento, prevenção, controle e mitigação do impacto à saúde pública, decorrentes dos acidentes com abelhas africanizadas, em nível local. A elaboração de metodologia de análise espacial em ambiente de SIG possibilita adquirir, recuperar, transformar e analisar dados georreferenciados relacionados ao objeto de estudo, no caso Apis mellifera, emitindo informações espaciais e temporais. Entre essas informações se consideram relevantes àquelas referentes ao manejo nos apiários, enxameações reprodutiva e de abandono, acidentes humanos com abelhas, uso e ocupação do solo no entorno dos apiários, presença de barreiras naturais e antrópicas, calendário apícola local (ciclos de floração de uma região por espécie; safras e entressafras), localização de centros especializados de atendimento de acidentes com abelhas (atendimento primário e intoxicações) e de retirada de enxames viajantes ou colmeias em posição de risco de acidentes. Dessa forma, sugere-se a formação de uma Rede de Informações da Apicultura e Riscos de Acidentes com abelhas, cujas informações mencionadas anteriormente, entre outras, sejam atualizadas periodicamente em ambiente de SIG.

\section{CONSIDERAÇÕES FINAIS}

A nocividade da abelha africanizada, ou seja, do conjunto de populações polihíbridas de Apis mellifera L. presente em território brasileiro, permite caracterizá-la como espécie exótica invasora nociva, de acordo com a Portaria no 1.138/GM/MS (23/05/2014). 
A Instrução Normativa IBAMAn ${ }^{0} 141$ (19/12/2006) no seu art. $4^{\circ}$ declara que o estudo, manejo ou controle da fauna sinantrópica nociva, previstos em programas de âmbito nacional, desenvolvidos pelos órgãos federais da Saúde e da Agricultura, bem como pelos órgãos a eles vinculados, serão analisados e autorizados pela DIFAP (Diretoria de Fauna e Recursos Pesqueiros)ou pelas Superintendências do IBAMA nos estados, de acordo com a regulamentação específica vigente. $\mathrm{E}$, no seu $\S 1^{\circ}$ comenta que observada a legislação e as demais regulamentações vigentes, inclui as abelhas entre os artrópodes nocivos passíveis de controle por órgãos de governo da Saúde, da Agricultura e do Meio Ambiente, sem a necessidade de autorização por parte do IBAMA. Entretanto, para cada estado e município é exigido umdocumento de órgão público competente, que ateste, publicamente, sua classificação como EEI (espécie exótica invasora), sua nocividade (fauna sinantrópica nociva)e a necessidade de manejo e controle de sua população, quando em situações de risco à saúde pública (ocorrência de acidentes).

Alerta-se que o risco de acidentes com essas abelhas varia segundo a realidade do uso e ocupação do solo em nível municipal, pois, cada vez é maior sua proximidade à população humana, tanto no ambiente rural como urbano, devido a sua capacidade de utilizar grande variedade de locais e estruturas antrópicos para nidificar.E, esse risco aumenta segundo a qualidade do manejo, a sanidade nos apiários aí localizados e a qualidade do pasto apícola.

Ressalta-se a iniciativa do Ministério Público do Estado da Bahia como referência para os demais municípios brasileiros, que por meio do seu órgão técnico consultor CEAMA (2016), indicou medidas para a criação de mecanismos legais, que possibilitem a regulamentação do atendimento aos acidentes envolvendo abelhas africanizadas nos centros urbanos. Esses acidentes representam risco iminente ao meio ambiente e à saúde pública, justificando, a intervenção do Ministério Público, visando orientar e acelerar o processo de regulamentação e definição das competências do poder público estadual ou municipal na atuação em conjunto, ou não, nesse âmbito, nas áreas urbanas de Salvador e do Estado da Bahia. Destacam-se as recomendações fornecidas pelo CEAMA, aplicáveis às diversas realidades brasileiras, que atendendo o exposto no art. $3^{\circ}$ da Portaria 1.138 (23/05/2014), sugere que o controle e manuseio das abelhas, deverão envolver o máximo de atividades de apoio, visando: 
1- a eliminação sistemática de condições favoráveis de enxameagens, a exemplo de redução de abrigo para as abelhas africanizadas, influenciando assim, positivamente na redução de outros agravos da saúde pública;

2- o estabelecimento de parcerias, entendidas como acordo entre órgãos públicos, para a criação de um grupo ou núcleo executivo operacional, que deverá contar com o envolvimento da vigilância epidemiológica, dos órgãos de meio ambiente, da polícia militar e do Corpo de bombeiros;

3- ações de recolhimento e de destinação correta das colmeias, visando seu aproveitamento para a produção de mel e preservação da sua função biológica como espécie polinizadora em conformidade com o Decreto 4.339/2002 da Política Nacional da Biodiversidade;

4- Estabelecer rotinas para ações de contenção, controle e monitoramento das abelhas africanizadas em áreas urbanas;

5- Utilizar campanhas educativas visando sensibilizar a população para o não extermínio da espécie inadvertidamente, bem como socializar informações sobre medidas preventivas para evitar os acidentes envolvendo as abelhas africanizadas;

6- Atender à população em caso de necessidade de remoção de colmeias estabelecidas, assim como de enxameagens (telefone/whatsapp/e-mail/site);

7- Cadastrar apicultores para recebimento de colônias removidas de áreas urbanas;

8- Treinar técnicos para a remoção e transporte das colônias;

9- Remover e decidir o destino das colônias;

10- Erradicar a colmeia in loco quando necessário e possível.

Acrescenta-se a essas recomendações a adoção de medidas de biossegurança que impeçam ou minimizem o risco da ocorrência de acidentes causados pelas abelhas relacionados à execução das atividades de vigilância, segundo orientações fornecidas em SEBRAE (2013), CORREIA-OLIVIEIRA et al. (2012) e SOARES (2012).

Verifica-se, por meio da Portaria n ${ }^{0} 1.138$ (23/05/2014),que as ações e os serviços de saúde voltados para vigilância, prevenção e controle de abelhas africanizadas, cabe ao serviço de vigilância em Saúde, por meio de suas Regionais de Saúde. Essas regionais se responsabilizam pelo registro e atendimento dos casos nos quais se verifica acidentes com abelhas envolvendo a população humana. Segundo o art. $4^{\circ}$ da Portaria $n^{\circ} 1.138(23 / 05 / 2014)$ 
os estabelecimentos responsáveis por vigilância de zoonoses pertencentes ao SUS e os serviços voltados para a vigilância, a prevenção e o controle de zoonoses e de acidentes causados por animais peçonhentos e venenosos, de relevância para saúde pública, deverão ser inscritos no Sistema de Cadastro Nacional de Estabelecimento de Saúde (SCNES), utilizando critérios de cadastramento que serão regulamentados em portaria específica do Secretário de Vigilância em Saúde do Ministério da Saúde.

Desta forma, conclui-se que a identificação de medidas de planejamento e tomada de decisão na redução dos acidentes com abelha africanizada (Apis mellifera), em tempo oportuno, se faz cada vez mais necessária, tanto no campo como na área urbana. Para tanto, sugere-se a elaboração de metodologia de notificação e investigação de eventos adversos (fatores de risco e acidentes com abelhas), atualizados no tempo e no espaço, associados às abelhas para o controle da propagação das mesmas no ambiente rural e urbano.

É nesse contexto, que se vislumbra a aplicação da elaboração de uma metodologia de diagnóstico e análise espacial em ambiente de SIG, em rede, partindo das experiências relatadas referentes aos estudos de acompanhamento da sanidade e produtividade dos apiários. O SCNES apresenta-se como uma importante fonte de dados, mas para sua aplicação como fonte de dados para monitoramento do risco de acidentes com abelhas africanizadas, necessita-se que tais informações sejam atualizadas diariamente. A eficácia e eficiência desse sistema exige, também, a garantia da rapidez na transferência dos dados notificados (ex.: tipos de acidentes, qualidade do atendimento, número e locais de enxames de pouso ou alojados e de remoções, uso de caixas-iscas, uso e ocupação do solo, sanidade e produtividade nos apiários e etc.), assim como informações das ações preventivas e de controle. Tendo como produto a rápida formação e manipulação de cenários (avaliações e manipulações espaciais), em nível local e regional, para a tomada de decisão, em tempo oportuno, espera-se minimizar o número de acidentes com abelhas, assim como uma melhor evolução dos quadros dos acidentes humanos. Importante medida de prevenção dos acidentes com abelhas consiste na qualidade do nível de informação da população local em área de risco, no que se refere aos cuidados para prevenir acidentes. Além disso, após a ocorrência do acidente, é de grande importância a rapidez nos procedimentos de primeiros socorros e também na busca de auxílio especializado no Centro de Informação e Assistência Toxicológica (CIAT) de referência a fim de se obter as instruções necessárias para o pronto-socorro pré-hospitalar. Estas são medidas que podem ser vistas como fundamentais para a melhor evolução do quadro, no caso de acidentes com abelhas africanizadas. 


\section{REFERÊNCIAS}

ALMEIDA, G. F. Fatores que interferem no comportamento enxameatório de abelhas africanizadas. 2008. 120 f. Tese (Doutorado em Entomologia) - Faculdade de Filosofia, Ciências e Letras de Ribeirão Preto, Universidade de São Paulo. Ribeirão Preto, SP. 2008. Disponível em $<$ http://www.ffclrp.usp.br/imagens defesas/ $02 \quad 05 \quad 2013 \quad 16 \quad 15 \quad 32$ 45.pdf $>$. Acesso em 18 de janeiro de 2016.

ASSOCIAÇÃO BRASILEIRA DE ESTUDOS DAS ABELHAS (A.B.E.L.H.A.). Associação civil, sem fins lucrativos e conotação político-partidária ou ideológica, com o objetivo de liderar a criação de uma rede em prol da conservação de abelhas e outros polinizadores. 2015. Disponível em: < $\underline{\text { http://abelha.org.br/faq- }}$ abelha/>. Acesso em 18 de janeiro de 2016.

BARCELlOS, C.; BASTOS, F. I. Geoprocessamento, ambiente e saúde: uma união possível?. Cadernos de Saúde Pública, Rio de Janeiro-RJ, v.12, n.3, p.389-397. $1996 . \quad$ Disponível em<http://www.scielo.br/pdf/\%0D/csp/v12n3/0264.pdf $>$. Acesso em 12 de abril de 2016.

BARCELLOS, C.; RAMALHO, W. Situação atual do Geoprocessamento e da análise de dados espaciais em saúde no Brasil. Informática Pública, Belo Horizonte-MG, v.4, n.2, p.221-230, 2002. Disponível em<http://www.arca.fiocruz.br/xmlui/bitstream/handle/icict/768/BARCELLOS_Situacao\%20atual\%20do\%20ge oprocessamento_2002.pdf?sequence=2>. Acesso em 12 de abril de 2016.

BATISTA, C. W. A. Análise dos casos de acidentes causados por abelhas e vespas em um Centro de Controle de Intoxicação em um município paraibano. 2015. 19 f. Trabalho de Conclusão de Curso (Graduação em Farmácia) - Departamento de Farmácia, Universidade Estadual da Paraíba. Campina Grande, PB. 2015. Disponível em <http://dspace.bc.uepb.edu.br/jspui/bitstream/123456789/8236/1/PDF\%20\%20Clauberth\%20Weerner\%20Ara \%C3\%BAjo\%20Batista.pdf >. Acesso em 18 de janeiro de 2016.

BRASIL. Ministério da Saúde. Esclarecimento sobre a Portaria n ${ }^{\circ}$ 1.138/GM/MS, de 23 de maio de 2014. Define [esclarecimento sobre] as ações e os serviços de saúde voltados para vigilância, prevenção e controle de zoonoses e de acidentes causados por animais peçonhentos e venenosos, de relevância para a saúde pública. 30 de set. de 2014a. Disponível em <http://portalsaude.saude.gov.br/index.php/o-ministerio/principal/leia-mais-oministerio/197-secretaria-svs/14874 esclarecimento-sobre-a-portaria-n-1-138-gm-ms-de-23-de-maio-de-2014>. Acesso em 29 de dezembro de 2015.

BRASIL. Ministério da Saúde. Portaria no 1.138/GM/MS, de 23 de maio de 2014. Define as ações e os serviços de saúde voltados para vigilância, prevenção e controle de zoonoses e de acidentes causados por animais peçonhentos e venenosos, de relevância para a saúde pública. 2014b. Disponível em

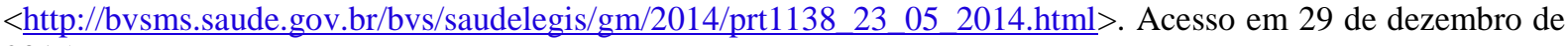
2015.

BRASIL. Ministério do Meio Ambiente. Espécies exóticas invasoras. Brasília, DF: Ministério do Meio Ambiente (MMA), 2012. Disponível em<http://www.mma.gov.br/biodiversidade/biosseguranca/especiesexoticas-invasoras $>$. Acesso em 19 de janeiro de 2016

BRASIL. Ministério do Trabalho e Emprego. Prevenção de acidentes com animais peçonhentos. FUNDACENTRO (Fundação Jorge Duprat Figueiredo de Segurança e Medicina do Trabalho). (Manual). 1 ed. São Paulo, SP, 2001. 46p. Disponível em<http://www.fundacentro.gov.br/biblioteca/bibliotecadigital/publicacao/detalhe/2012/7/prevencao-de-acidentes-com-animais-peconhentos $>$. Acesso em 29 de dezembro de 2015.

BRITO, R. L. Sistema de informação geográfica aplicado ao diagnóstico do ácaro Varroa destructor em apiários na região nordeste do Brasil. 2014. 63 f. Dissertação (Mestrado em Ciência Animal nos Trópicos) Escola de Medicina Veterinária e Zootecnia, Universidade Federal da Bahia. Salvador, BA. 2014. Disponível em<http://www.mevtropical.ufba.br/arquivos/dissertacoes/2012/britorl.pdf $>$.Acesso em 29 de dezembro de 2015 . 
CÂMARA, G.; MEDEIROS, J. S. Princípios básicos em geoprocessamento. In: ASSAD, E.D.; SANO, E. E. (Ed.). Sistema de informações geográficas: aplicações na agricultura. 2. ed. Brasília: Serviço de Produção de Informação, 1998. cap.1, p.1-29.

CAMARGO, R. C. R.; PereirA, F. M.; LOPES, M. T. R. Sistema de Produção de Mel. Teresina: EMBRAPA Meio Norte, 2002.

CAMARGO, S. C. Aplicação de um Sistema de informações geográficas (SIG) no estudo da apicultura na região oeste do Paraná. 2011. [71 f.]. Dissertação (Mestrado em Zootecnia) Universidade Estadual do Oeste do Paraná. Marechal Cândido Rondon, PR. 2011. Disponível em<http://tede.unioeste.br/tede/tde arquivos/8/TDE2013-01-29T093829Z-909/Publico/Simone_Cristina_Camargo.PDF>Acesso em 29 de dezembro de 2015.

CARNEIRO, W. M. A. (Coord.). Produção e venda dos produtos da apicultura no Nordeste. Informe Rural ETENE.Fortaleza: Banco do Nordeste do Brasil, 2010. [7 p]. (Ano 4, n.10). Disponível em $\langle$ http://www.bnb.gov.br/documents/88765/89729/ire_ano4_n10.pdf/8c293cbe-c24f-4abc-909c-7cc2109d8663>. Acesso em 18 de janeiro de 2016.

CEAMA. Centro de Apoio Operacional do Meio Ambiente e Urbanismo. Nota técnica sobre manejo de abelhas africanizadas. Instruções para a criação de regulamentação visando o controle e manejo ambiental como atividade de rotina no combate aos acidentes com abelhas africanizadas nos centros urbanos do Estado da Bahia. Bahia,[2016]. [5 p.]. Disponível em <http://www.ceama.mp.ba.gov.br/biblioteca-virtualnusf/doc view/3834-nota-tecnica-sobre-manejo-abelhas-africanizadas-final-em-janeiro-de-2016.html>. Acesso \begin{tabular}{llllll}
\hline $\mathrm{em}$ & 02 & $\mathrm{de}$ & fevereiro & de &
\end{tabular}

CONABIO. Comissão Nacional de Biodiversidade. Resolução $n^{\circ}$ 05, de 21 de outubro de 2009. Dispõe sobre a Estratégia Nacional sobre Espécies Exóticas Invasoras. Brasília, DF: Ministério do Meio Ambiente e Secretaria de Biodiversidade e Florestas (MMA/SBF), 2009. 23 p. Disponível em 〈http://www.mma.gov.br/biodiversidade/biosseguranca/especies-exoticas-invasoras/estrategia-nacional〉 $\quad$ e <http://www.mma.gov.br/estruturas/174/_arquivos/anexo_resoluoconabio05_estrategia_nacional_espcies_inv asoras_anexo_resoluoconabio05_174.pdf $>$. Acesso em 29 de dezembro de 2015.

CORREIA-OLIVIEIRA, M. E.; NUNES, L. A.; SILVEIRA, T. A.; MARCHINI, L. C.; SILVA, J. W. P. Manejo da agressividade de abelhas africanizadas. Piracicaba: ESALQ - Divisão de Bibliotecas, 2012. 38 p. (Série Produtor $\quad$ Rural, $\quad n . \quad 53)$. $<$ http://www4.esalq.usp.br/biblioteca/sites/www4.esalq.usp.br.biblioteca/files/publicacoes-avenda/pdf/SPR53.pdf $>$. Acessoem 02 de fevereiro de 2016.

DE JONG, D. Africanized honey bees in Brazil, forty years of adaptation and success. Bee World, UK,v.77, n.2, p.67-70, 1996. Disponível em 〈http://www.tandfonline.com/doi/pdf/10.1080/0005772X.1996.11099289>. Acesso em 18 de janeiro de 2016.

EMBRAPA. Empresa Brasileira de Pesquisa Agropecuária. Produção de mel. 2002. Disponível em <https://sistemasdeproducao.cnptia.embrapa.br/FontesHTML/Mel/SPMel/historico2.htm〉. Acesso em 19 de janeiro de 2016.

FAQUINELLO, P. Avaliação genética em abelhas Apis mellifera africanizadas para produção de geleia real. 2007. 54 f. Dissertação (Mestrado em Zootecnia) - Centro de Ciências Agrárias, Universidade Estadual de Maringá. Maringá, PR. 2007. Disponível em <http://ppz.uem.br/trabalhos-deconclusao/dissertacoes/2007/patricia-faquinello>. Acesso em 29 de dezembro de 2015.

FRANCESCHINELLI, E. V.; ALMEIDA, E. A. B.; ANTONINI, Y.; CABRAL, B. C.; CARMO, R. M.; DAMASCENO, A.; FONTENELLE, J. C. R.; GARCIA, V. L. A.; GUILHERME, M. S.; LAPS, R. R.; LEITÃO, G. G.; LEITÃO, S. G.; MIKICH, S. B.; MOREIRA, D. L.; NASCIMENTO, M. T.; NEMÉSIO, A.; RIBON, R.; SILVEIRA, F. A.; VIDIGAL, T. H. D. A. Interações entre animais e plantas, p. 275-296. In: RAMBALDI, D. M.; OLIVEIRA, D. A. S. (Orgs.). Fragmentação de ecossistemas: causas e efeitos sobre a biodiversidade e recomendações de políticas públicas. Brasília, DF: Ministério do Meio Ambiente e Secretaria de Biodiversidade e Florestas (MMA/SBF) [Dupligráfica], 2003. 508 p. 
IBAMA. Instituto Brasileiro do Meio Ambiente e dos Recursos Naturais Renováveis. Instrução Normativa $\mathrm{n}^{\circ}$ 141, de 19 de dezembro de 2006 (D.O.U. de 20/12/06). Regulamenta o controle e o manejo ambiental da fauna sinantrópica nociva. Disponível em <http://www.ambiente.sp.gov.br/fauna/files/2015/09/documentos_legislao_25.pdf >. Acesso em 29 de dezembro de 2015.

MANGABEIRA, J. A. C. Tipificação de produtores rurais apoiada em imagens de alta resolução espacial, geoprocessamento e estatística multivariada: uma proposta metodológica. 2002. Dissertação (Mestrado em Engenharia Agrícola) - Faculdade de Engenharia Agrícola, Universidade Estadual de Campinas, Campinas, 2002. Disponível em<http://www.tipifica.cnpm.embrapa.br/>. Acesso em 12 de abril de 2016.

MELlO, M. H. S. H.; SILVA, E. A.; NATAL, D. Abelhas africanizadas em área metropolitana do Brasil: abrigos e influências climáticas. Revista de Saúde Pública, São Paulo-SP, v.37, n.2, p.237-241, 2003. Disponível em <http://www.scielosp.org/pdf/rsp/v37n2/15292.pdf>. Acesso em 29 de dezembro de 2015.

MISTRO, D. C.; RODRIGUES, L. A. D.; FERREIRA JÚNIOR, W. C. The Africanized honey bee dispersal: a mathematical zoom.Bulletin of Mathematical Biology, Claremont-CA-USA, v.67, n.2, p.281-312, 2005. Disponível em <http://link.springer.com/article/10.1016/j.bulm.2004.07.006\#/page-1>. Acesso em 18 de janeiro de 2016.

PAUlA NETO, F. L.; ALMEIDA NETO, R. M. Apicultura nordestina: principais mercados, riscos e oportunidades. Fortaleza: Banco do Nordeste do Brasil, 2006. 78 p. (Série Documentos do ETENE, n. 12). Disponível em <http://www.bnb.gov.br/projwebren/exec/livroPDF.aspx?cd_livro=5>. Acesso em 18 de janeiro de 2016.

PAULA, R. V. Sistemas de informações geográficas destinado ao planejamento da atividade apícola no assentamento de "Padre Josimo Tavares"- PA. 2009. 84 f. Dissertação (Mestrado em Geografia Física) Faculdade de Filosofia, Letras e Ciências Humanas, Universidade de São Paulo. São Paulo, SP, 2009. Disponível em<http://www.teses.usp.br/teses/disponiveis/8/8135/tde-02022010-144613/>. Acesso em 20 de fevereiro de 2016.

PEDROSO, L. G.; FEITOSA, C. O. Contrastes da produção de mel de abelhas na região Sul e Nordeste do Brasil: possibilidade de expansão da atividade no Nordeste. In: SOCIEDADE BRASILEIRA DE ECONOMIA, ADMINISTRAÇÃO E SOCIOLOGIA RURAL - SOBER NORDESTE, 8., 2013, Parnaíba. Anais...Parnaíba: UFPI, nov. 2013. 20 p. Disponível em <http://www.viiisoberne.com.br/anais/ARQUIVOS/GT1-241-109-2013 0930174234.pdf>. Acesso em 29 de dezembro de 2015.

PEREIRA, S. A. N.; SOUSA, C. S. Levantamento da fauna de abelhas no município de Monte Carmelo-MG. Getec, Monte Carmelo-MG, v.4, n.7, p.11-24, 2015. Disponível em <http://www.fucamp.edu.br/editora/index.php/getec/article/view/536/386 >. Acesso em 19 de janeiro de 2016.

RAMBALDI, D. M.; OLIVEIRA, D. A. S. (Orgs.). Fragmentação de ecossistemas: causas, efeitos sobre a biodiversidade e recomendações de políticas públicas. Brasília, DF: Ministério do Meio Ambiente e Secretaria de Biodiversidade e Florestas (MMA/SBF) [Dupligráfica], 2003. 510 p. Disponível em <http://www.mma.gov.br/estruturas/chm/_arquivos/fragment.pdf $>$. Acesso em 29 de dezembro de 2015.

SANDES JÚNIOR, R. L. Estudo de ocorrências de enxames migratórios do gênero Apis na cidade do Salvador no período de 2000 a 2004. 2007. 80 f. Dissertação (Mestrado em Ciência Animal nos Trópicos) Escola de Medicina Veterinária, Universidade Federal da Bahia. Salvador, BA. 2007. Disponível em <http://www.mevtropical.ufba.br/arquivos/dissertacoes/2005/renato\%20lemos.pdf >. Acesso em 18 de janeiro de 2016.

SANTOS, M. F. Relação entre diversidade polínica e a produção de mel de Apis mellifera L. frente as atividades antrópicas no sudoeste de Mato Grosso. 2011. 111 f. Dissertação (Mestrado em Ciências Ambientais) - Universidade do Estado de Mato Grosso. Cáceres, MT. 2011. Disponível em<http://portal.unemat.br/media/oldfiles/ppgca/docs/dissertacao_milaine_fernandes.pdf $>$. Acesso em 29 de dezembro de 2015. 
SANTOS, R. F; CARVALHAIS, H. B.; PIRES, F. Planejamento ambiental e sistemas de informações geográficas. Cadernos de Informações Georreferenciadas,FEC/UNICAMP, v.1, n.2, 1997. Disponível em $<$ http://orion.Cpa.unicamp.br/html/civ1n2a2.html>. Acesso em 22 de novembro de 2005.

SEBRAE. Serviço de Apoio às Micro e Pequenas Empresas. (PE). Boletim setorial do agronegócio: Apicultura. Recife, PE. Maio de 2011. 24 p. Disponível em $\langle$ http://www.sebrae.com.br/Sebrae/Portal\%20Sebrae/ Anexos/boletim-apicultura.pdf $>$. Acesso em 19 de janeiro de 2016.

SEBRAE. Serviço de Apoio às Micro e Pequenas Empresas; SIS. Sistema de Inteligência Setorial. (SC). Acidentes com abelhas: compreensão para a prevenção. Relatório de Inteligência Analítico [sobre] Apicultura. Florianópolis, SC: Junho de 2013. 10 p. Disponível em <https://sis.sebrae-sc.com.br/produtos/relatorios-deinteligencia/acidentes-com-abelhas-compreensao-para-a-prevencao/54c6815df17388e7058b4d80>. Acesso em 18 de janeiro de 2016

SILVA, C. I.; ALEIXO, K. P.; NUNES-SILVA, B.; FREITAS, B. M.; IMPERATRIZ-FONSECA, V .L. Guia ilustrado de abelhas polinizadoras no Brasil. 1. ed. São Paulo, SP: [s.n.], 2014. Disponível em <http://www.semabelhasemalimento.com.br/wp-content/uploads/2015/02/Guia_abelhaspolinizadoras_02_junho_20 14-1_web.pdf>. Acesso em 18 de janeiro de 2016.

SILVA, R. C. P. A.; PEIXE, B. C. S. Estudo da cadeia produtiva do mel no contexto da apicultura paranaense: uma contribuição para a identificação de políticas públicas prioritárias. In: SEMINÁRIO DE POLÍTICAS PÚBLICAS NO PARANÁ: ESCOLA DE GOVERNO E UNIVERSIDADES ESTADUAIS, 1., 2008. Curitiba, Anais... Curitiba: UFPR, 31 de julho e 1 de agosto de 2008. [29 p.].Disponível em <http://www.escoladegoverno.pr.gov.br/arquivos/File/anais/painel_agricultura/estudo da cadeia.pdf $>$. Acesso em 18 de janeiro de 2016.

SOARES, A. E. E. Abelhas africanizadas no Brasil: do impacto inicial às grandes transformações. In: REUNIÃO ANUAL DA SOCIEDADE BRASILEIRA PARA O PROGRESSO DA CIÊNCIA, 64, 2012, São Luís. Anais...São Luís: UFMA, jul. 2012. n.p. Disponível el <http://www.sbpcnet.org.br/livro/64ra/PDFs/arq_2061_450.pdf>. Acesso em 29 de dezembro de 2015.

WINSTON, M.L. 2003. A biologia da abelha. Porto Alegre: Magister, 2003. 